\section{Evolution of uterine cervical cancer mortality from 1979 to 1998 in the State of Rio Grande do Sul, Brazil}

\author{
A evolução da mortalidade por câncer \\ de colo de útero entre 1979 e 1998 \\ no Rio Grande do Sul, Brasil
}

Luciane Kalakun 1

Mary Clarisse Bozzetti 2

\footnotetext{
1 Hospital de Clínicas de Porto Alegre, Universidade Federal do Rio Grande do Sul, Porto Alegre, Brasil.

2 Faculdade de Medicina, Universidade Federal do Rio Grande do Sul, Porto Alegre, Brasil.

Correspondence L. Kalakun Serviço de Genética Médica, Hospital de Clínicas de Porto Alegre, Universidade Federal do Rio Grande do Sul. Rua Ramiro Barcelos 2350 , Porto Alegre, RS 90035-903, Brasil. lkalakun@hcpa.ufrgs.br
}

\begin{abstract}
A decrease in uterine cervical cancer (CC) mortality has been observed in developed countries. However, mortality data in Brazil suggest that CC is one of the most frequent causes of cancer death in women; it is the fourth cause of death from cancer in women in Rio Grande Sul State. A time-trend ecological study was performed to analyze CC mortality trends in Rio Grande do Sul from 1979 to 1998. Data were collected from the Mortality Information System, Brazilian Ministry of Health (DATASUS). Standardized mortality ratios were calculated and linear regression was used for time-trend analysis. The impact of cervical cancer death on life expectancy was also estimated for the study population using potential years of life lost (PYLL). Standardized mortality ratios during the study period revealed a positive linear trend of 0.17 , and the mean annual mortality rate was 7.58/100,000. Cervical cancer accounted for $21.9 \pm 1.33$ PYLL during the period. In conclusion, although CC is a preventable and curable disease, an increase is observed in mortality from this cause in Rio Grande do Sul State, which may suggest failure in screening programs for cervical cancer.
\end{abstract}

Cervical Intraepithelial Neoplasia; Mortality; Women's Health

\section{Introduction}

Uterine cervical cancer is one of the types of cancer with the highest incidence in women, since more than 471 thousand new cases are diagnosed per year worldwide 1 . However, a reduction has been observed in cervical cancer incidence and mortality in developed countries in the last 50 years due to systematic screening programs for the population at risk 2 .

The uterine cervical cancer mortality rate in Canada, for example, was 11/100 thousand women in 1951 and declined to $2.39 / 100$ thousand by 1995 3,4. In the United States the incidence of cervical cancer was 32.6/100 thousand women in the late 1940s and dropped to 7.9/100 thousand in 1989-1991, while the mortality rates also decreased, especially during the 1960 s and 70 s, with a mean reduction in both incidence and mortality rates of some $4.0 \%$ per year until the 1980s 5 . However, the situation has been different in developing countries, principally in Latin America, the Caribbean, and Asia, with an annual increase in both incidence and mortality rates. In such countries, cervical cancer is one of the most frequent types of cancer and accounts for more than $24.0 \%$ of all female cancers and for 6 deaths per 100 thousand women 6,7 .

In Brazil, uterine cervical cancer is fifth among all malignant neoplasms, with more than 16 thousand new cases per year, occupying sec- 
ond place among cancers in females. The highest incidence rates are in the North and Northeast regions 8. In Rio Grande do Sul (in the South), uterine cervical cancer also shows high mortality rates, occupying fifth place 9 .

Uterine cervical cancer thus poses a major public health problem, especially in developing regions and even where there are programs for prevention and early detection. Thus far the failure of screening programs has been considered one of the most important factors for high cervical cancer rates. In the United States it has been estimated that an interruption of such programs would lead to an increase of 200.0 to $300.0 \%$ in the risk of women developing this cancer over the course of their lives 10 .

Uterine cervical cancer can thus be seen as a common cause of female morbidity and mortality in Rio Grande do Sul State and Brazil as a whole, although it is one of the most curable cancers, since its initial stage is long and it is highly detectable, appearing to suggest that a large number of women lack access to detection methods or ignore the problem's importance. The current study aims to determine the uterine cervical cancer mortality trend among women in Rio Grande do Sul from 1979 to 1998 and relate it to the existence of official screening programs in the State, besides comparing these rates other States in Brazil and other countries, as well as evaluating the potential years of life lost (PYLL) by women as a consequence of early death from this disease.

\section{Method}

The study adopted a temporal series design, the target outcome of which was death from uterine cervical cancer, recorded as the basic cause of death on the death certificate. Data on mortality from uterine cervical cancer in Rio Grande do Sul were obtained from a database in the Mortality Information System of the Ministry of Health, available on CD-ROM or Internet (TabWin and TabNet programs, distributed by DATASUS under the MoH itself) 11 . The MIS includes available data on cause of death for the years 1979 through 1998, the period corresponding to this study. Coefficients for the years 1999, 2000, and 2001 were estimates obtained from the National Cancer Institute (INCA), demonstrating a possible negative trend in the number of deaths from this cause.

The collected data were grouped according to the seven meso-regions in the State of Rio Grande do Sul (Northeast, Central-West, Southwest, Southeast, Central-East, Greater Metro- politan Porto Alegre, and Northeast), defined according to the forms of organization of their territories based on their social process, natural background, and communications and community networks 12 .

Data were collected on age interval (WHO classification 13); schooling (classified as: none, primary, secondary, university, unknown); marital status (single, married, widow, legally separated, other, unknown); place of occurrence of death (hospital, public byways, home, other, unknown); and characteristics of the meso-regions, such as available hospital beds, gross domestic product, and rural population.

Causes of death were coded according to the International Classification of Diseases (ICD), 9th revision 14 , chapter 2 , which defines uterine cervical cancer in four sub-classes, namely: 180.0, endocervix; 180.1, exocervix; 180.8, other specified sites of cervix; 180.9, cervix uteri, unspecified; 179.0, malignant neoplasm of uterus, unspecified. This classification was used for the years de 1979 to 1995, and from 1996 on the classification corresponding to these diagnoses in ICD-10 was used 15.

The gross and age-standardized coefficients for Rio Grande do Sul State are described in relation to the Brazilian female population from the 2000 census. The age-standardized rates were calculated by the direct method 16. Coefficients for the meso-regions of Rio Grande do Sul State were standardized by age in relation to the population of Rio Grande do Sul from the 2000 census. For comparison of mortality from uterine cervical cancer in Rio Grande do Sul with other States of Brazil, we used the standard world population for the year 2000, and for comparison with other countries we used the world female population for 1995 (http://www.census.gov/ipc/www/idbagg.htm, accessed in Jan/2002).

Coefficients were calculated using the census populations, and for non-census years an interpolation was performed based on the census years.

Uterine cervical cancer mortality coefficients were analyzed by simple linear regression, considering that the data followed a distribution similar to the Gaussian curve, and for comparison purposes we used the curve from the third-order self-regressive integrated mobile means 16,17 .

Studies by Fonseca et al. 18 and Koifman et al. 19 provided the comparison criterion for deaths from uterine cervical cancer and unspecified malignant neoplasm of uterus, by signaling opposite trends over the course of the study period (1980-1998). Thus, the same crite- 
rion was followed in the analysis of the mortality coefficients in the current study, both for the State of Rio Grande do Sul and for the mesoregions and other States evaluated.

The means for potential years of life lost (PYLL) and potentially productive years of life lost (PPYLL) for the study population were analyzed for the 15-74-year age bracket for each year in the period studied 20. PYLL was calculated using age 75 years as the life expectancy for the female population in Rio Grande do Sul according to the 2000 census. PPYLL was calculated using 60 years, which is the reference age for women's retirement in Brazil.

Data were processed using Microsoft Excel ${ }^{\circledR}$, version 9.0, and the graphs and statistical analysis used Origin ${ }^{\circledR}$, version 5.0 .

\section{Results}

Rio Grande do Sul presented a total of 4,829 deaths from uterine cervical cancer from 1979 to 1998 , and the mean annual death rate during the period was $7.58 / 100$ thousand women.

Women who died of uterine cervical cancer were characterized as residing mainly in the Greater Metropolitan Porto Alegre meso-region $(49.5 \%)$, with $17.5 \%$ in the Northeast region and $33.1 \%$ distributed around the other mesoregions of the State. Level of schooling included $12.4 \%$ of illiterates and $39.1 \%$ with primary education, while $2.6 \%$ had secondary or university education; in $45.9 \%$ of the cases the information on schooling was "unknown". Fortyfive per cent of the deaths were in married women, and $49.4 \%$ were single, widows, or separated. Some $82.6 \%$ of the deaths occurred in hospital and $15.8 \%$ at home.

In the analysis of gross and standardized mortality from uterine cervical cancer in the State from 1979 (5.3/100 thousand) to 1998 (9.6/100 thousand), there was a relative increase of $81.0 \%$ in the gross coefficient and an even greater increase in the standardized coefficient, from 3.2 to 9.5 deaths per 100 thousand women, respectively, that is, $196.0 \%$. The upward trend in this mortality persisted even after the fluctuation in these rates was smoothed using the mobile means method, obtaining an annual increase of 0.17 in the coefficient, demonstrated in Figure 1. It is important to observe that the trend in the mobile means from unspecified malignant neoplasm of uterus was similar to that observed for uterine cervical cancer until the year 1983, when it became negative, with a negative annual increment in the angular coefficient $(-0,12)$.

Figure 1

Mobile means of standardized mortality coefficients for uterine cervical cancer and unspecified malignant neoplasm of uterus in Rio Grande do Sul State, Brazil, and graphs of gross and standardized coefficients for the two neoplasms, from 1979 to 1998 (standardized to the female population of Rio Grande do Sul State, 2000).
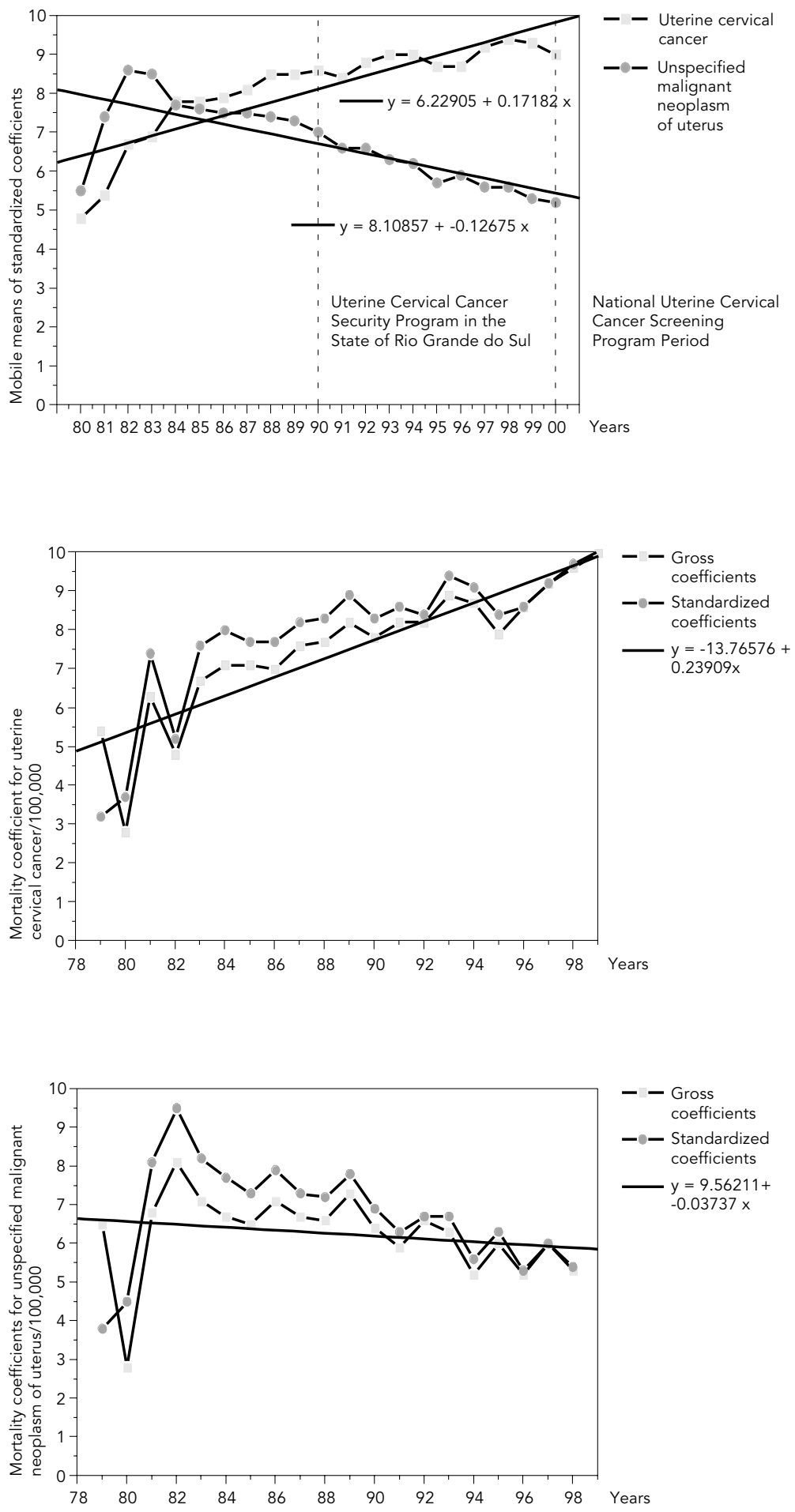
Based on data searches in the State Health and Environmental Department on screening programs in Rio Grande do Sul from 1979 to 1998, during the first decade there were no data recorded in such a way as can be retrieved. During the second decade of this series and up to 1999 , there was a statewide screening program based on Pap smears requested spontaneously by women. Beginning in the year 2000 , the uterine cervical cancer screening program in the State of Rio Grande do Sul was integrated into the National Uterine Cervical Cancer Screening Program known as Viva Mulher (http: //www.saude.gov.br/programas/mulher/ginec ol.htm). These periods are identified in the graph in Figure 1.

In the series studied, there was a wide variation in the potential years of life lost, from 18.7 to 24.1 years per woman who died of uterine cervical cancer from 1979 to 1998 , with a mean for the entire period of $21.9( \pm 1.33)$ years. The mean PPYLL for this period was $9.8( \pm 0.96)$ years, ranging from 7.2 to 11.2 . The highest mean PYLL and PPYLL occurred in 1985 and the lowest in 1979 (Figure 2).

In the analysis of age-standardized mortality coefficients for unspecified malignant neoplasm of uterus, in terms of PYLL and PPYLL, the distribution during the period was similar to that found for uterine cervical cancer, and the same was true for the means (respectively, $21.5 \pm 1.29$ years and $10 \pm 0.93$ years).

As for meso-regions in the State, the highest mean annual coefficient occurred in Greater Metropolitan Porto Alegre, with 9.72 deaths / 100 thousand women, followed by the Southwest (9.14 deaths/100 thousand women). The Southeast and Northwest meso-regions of the State had means of 7.18 and 6.87 deaths $/ 100$ thousand women, respectively, and the Central-West and Central-East showed means of 5.18 and 4.66 deaths / 100 thousand women, respectively. The lowest mean annual coefficient occurred in the Northeast meso-region, with 3.85 deaths/ 100 thousand women.

Comparing the mean annual coefficient for Rio Grande do Sul State (7.58/100 thousand women) with the meso-regions, we observed that Greater Metropolitan Porto Alegre and the Southwest showed higher mean annual coefficients than the State as a whole.

The tendency found in the distribution of mobile means for standardized mortality coefficients in all the meso-regions suggests a possible relationship between the increase in the mortality rates from uterine cervical cancer and the reduction in the rates from unspecified malignant neoplasm of uterus (Figure 3). At the beginning of the period, the uterine cervical cancer rates were lower than for unspecified malignant neoplasm of uterus, with the exception of Greater Metropolitan Porto Alegre, while at the end of the period all the meso-regions had uterine cervical cancer mortality coefficients that were higher than for unspecified malignant neoplasm of uterus, with one exception as well, namely the Central-East meso-region.

Figure 4 shows the distribution of the mobile means for mortality coefficients from uterine cervical cancer and unspecified malignant neoplasm of uterus in some States of Brazil. There was a wide variation in these rates among States during the study period.

In the States of Amazonas and Minas Gerais, we observed an inverse trend in the mortality rates from uterine cervical cancer and unspecified malignant neoplasm of uterus at the beginning of the study period. In Rio Grande do Sul State, this initial period was characterized by an increase in the coefficients for both these ICDs, with unspecified malignant neoplasm of uterus presenting the highest coefficients.

The State of Amazonas presented the highest mortality coefficients for the study period as a whole, but the highest coefficient was in 1985 (21.5/100 thousand women) in the Federal District of Brazil.

The States of Bahia and São Paulo and the Federal District showed a drop in the mortality coefficients from uterine cervical cancer. However, the mortality coefficients from unspecified malignant neoplasm of uterus in Bahia remained stable, in São Paulo they decreased, and in the Federal District they increased.

The largest increase in uterine cervical cancer during the study period was observed in the State of Rio Grande do Sul and the smallest was in the Federal District. Meanwhile, for unspecified malignant neoplasm of uterus, the largest decline was in the State of Amazonas (b = -0.17 ) and the smallest was in the State of Bahia $(b=-0.0017)$.

The standardized mortality ratio (SMR) for the population of Rio Grande do Sul in 1995 was $131.0 \%$ (95\%CI: 115.4-146.6) as compared to the population of Brazil as a whole, the population covered by a cervical cancer screening program similar to that of Rio Grande do Sul. When compared to the population of Norway (a country with an effective mortality control program for this disease), the SMR for the population of Rio Grande do Sul was $234.0 \%$ (95\%CI: 206.2-261.8). In other words, the deaths observed in the population of Rio Grande do Sul were well above the level expected if effective 
cervical cancer control programs existed, similar to those in Norway.

The uterine cervical cancer mortality rates in the State of Rio Grande do Sul have remained high, characterizing it as a disease of developing countries, represented in Figure 5 by Costa Rica, Mexico, Argentina, Brazil, and Cuba (data from 1995). Note that the mortality coefficient for Rio Grande do Sul in 1995 was only surpassed by Costa Rica and Mexico.

\section{Discussion}

We analyzed data for 4,829 deaths from uterine cervical cancer from the years 1979 to 1998 in the State of Rio Grande do Sul. According to the data in this study, the increase in the number of women who die from this cause has persisted over the years in the State.

The distribution of deaths by age interval in Rio Grande do Sul shows a higher frequency in the 35-to-54-year age interval (44.0\%). This coincides with the trend observed in developed countries, attributing this increased frequency to improved diagnostic precision and changes in women's lifestyles, exposing them to various risk factors $2,7,21$.

Deaths in the 15-to-24-year age interval in this study should be interpreted with caution, although an increase in deaths from uterine cervical cancer has been observed in younger women. Earlier initiation of sexual activity (exposing women prematurely to infectious agents like the human papillomavirus or HPV, implicated in the development of uterine cervical cancer) has been associated with this phenomenon. Despite possible data errors, such as incorrectly recorded age, we believe that these findings do not alter the upward mortality trend found in the study over the length of the period in Rio Grande do Sul, considering that the frequency for this age interval was quite low $(0.68 \%)$.

Factors that increase the population's susceptibility to risk factors for uterine cervical cancer include precarious living conditions, directly associated with low socioeconomic status. Lack of access to health services not only impedes poor women from being diagnosed, but also hinders their opportunity to receive adequate treatment in time to achieve cure.

The uterine cervical cancer mortality trend in Rio Grande do Sul at the beginning of the period partially reflects this reality, since an increase in mortality was observed, even though flaws in diagnosis of cause of death may have occurred during this period. Considering that
Figure 2

Distribution of potential years of life lost (PYLL) and potentially productive years of life lost (PPYLL) per woman due to uterine cervical cancer (UCC) and unspecified malignant neoplasm of uterus (UMNU) in Rio Grande do Sul State, Brazil, from 1979 to 1998.
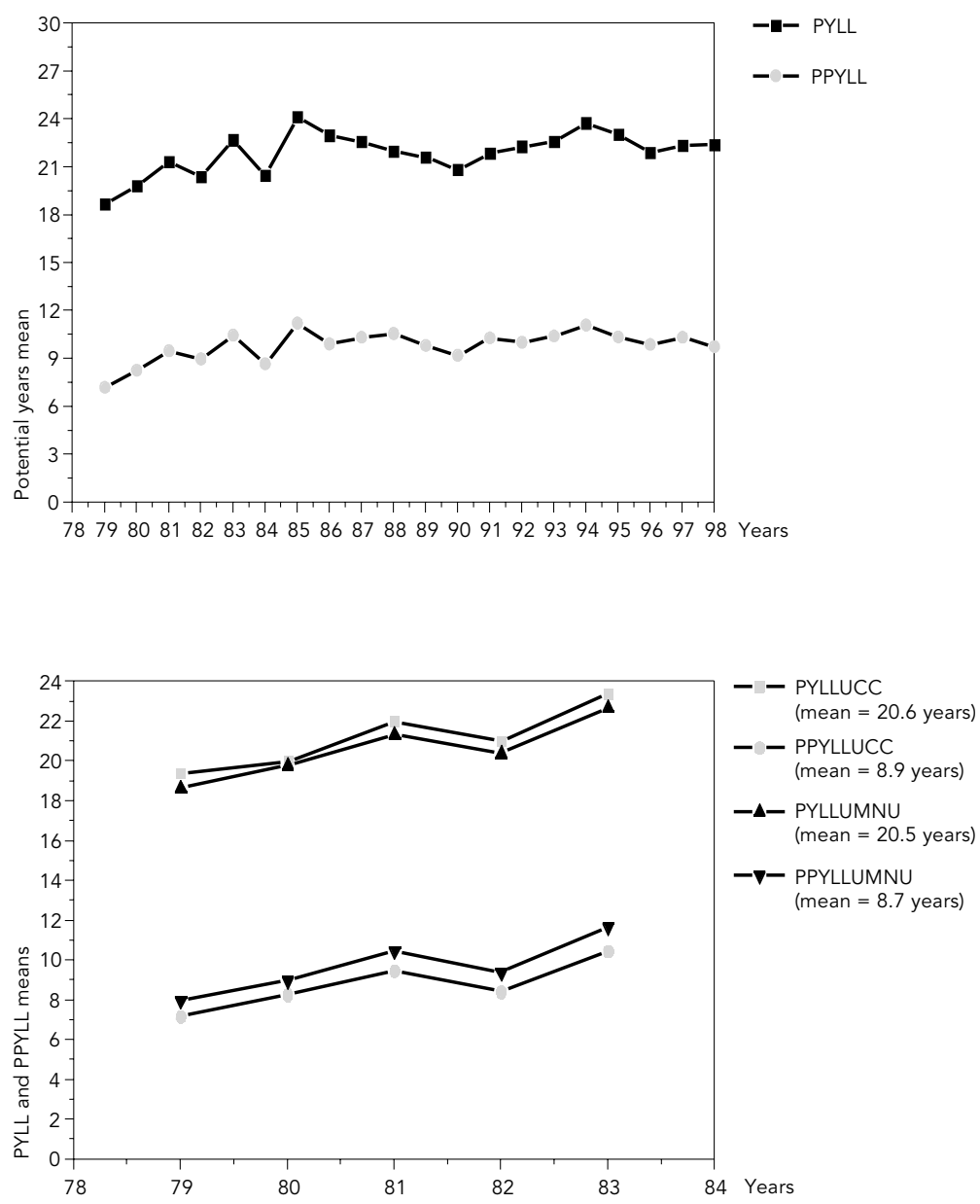

the designation for unspecified malignant neoplasm of uterus can encompass cervical neoplasms, which at the time of diagnosis may already have reached an advanced stage, it is logical to suppose that diagnoses recorded on death certificates during this period may have been incorrectly classified.

Still, there appears to have been an improvement in diagnosis of uterine cervical cancer and more correct filling-out of death certificates over the course of the study period, since the mortality coefficients from this disease increased even while those from unspecified malignant neoplasm of uterus decreased. Never- 


\section{Figure 3}

Distribution of mobile means of mortality coefficients for uterine cervical cancer and unspecified malignant neoplasm of uterus in meso-regions of Rio Grande do Sul State, Brazil (standardized to the female population of Rio Grande do Sul State, 2000).
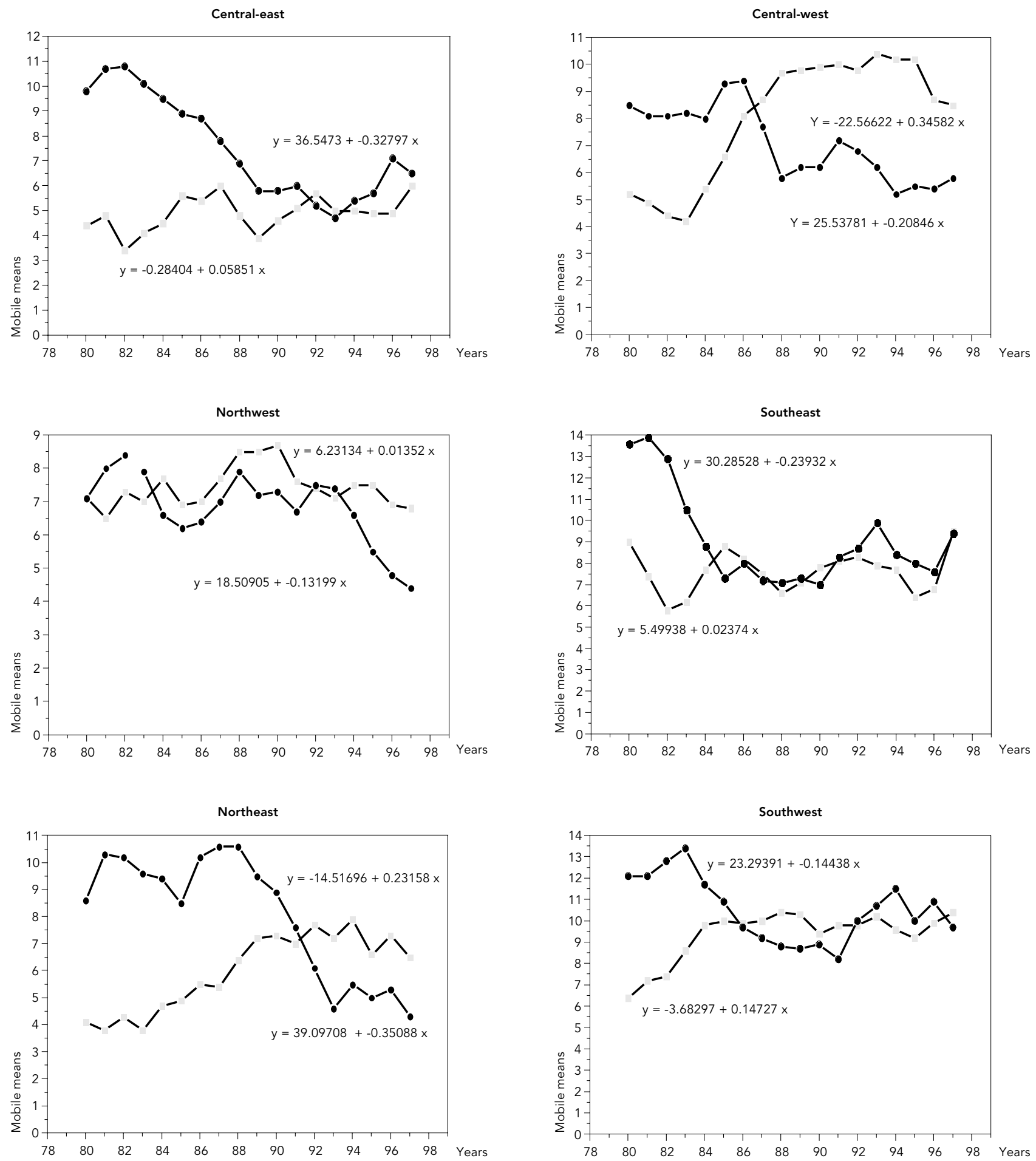

(continues) 
theless, even hypothesizing that $100.0 \%$ of the decrease in deaths with a diagnosis of unspecified malignant neoplasm of uterus results from improved classification of the diagnosis of uterine cervical cancer and that this contributed to increased mortality from this cancer, we still observe an increase in this mortality, independently of classification error, suggesting a real positive linear trend.

The estimates for the period after 1998 point to a change in the trend with uterine cervical cancer mortality coefficients. However, data obtained from INCA pertain to estimates based on the Mortality Information System, calculated from the mean rate from the last five years with known information, with the possibility of modifying a final analysis of the mortality coefficients trend.

Another possible reason for the continuing increase in the mortality coefficients in the State may relate to the lack of organized, systematic screening programs for uterine cervical cancer. Information from the State Health Department (verbal communication) corroborates this hypothesis.

Ministry of Health data showing Rio Grande do Sul State with a colposcopy coverage rate of $9.67 \%$ for women in 1996 come from programs that appear to confirm the increase in the number of deaths from this cause (http://www. saude.gov.br/programas/mulher/ginecol.htm, accessed on 20/Aug/2001). Even though low coverage may have occurred for Pap smears in Rio Grande do Sul, it is important to consider problems related to the quality of cytological exams. Uterine cervical adenocarcinoma is viewed as entailing pre-malignant lesions that are difficult to detect by this method and colposcopy, whose diagnoses present very low specificity $(15.0 \%)$, as an example of this type of problem 7,22,23.

The data from meso-regions suggest that the Northeast of Rio Grande do Sul presented the lowest annual uterine cervical cancer mortality coefficient during the study period. Meanwhile Greater Metropolitan Porto Alegre and the Southwest meso-region showed the highest mean annual coefficients. These regions are characterized as having combined urban-industrialized and rural populations. A study on overall cancer mortality suggests lower rates in non-industrialized areas 24 . In addition, a major portion of the lower-income population is concentrated on the outskirts of large cities, with the highest rates of sexually transmitted diseases, thus characterizing greater multiplicity of sexual partners and also more limited access to health services, which is certainly a fa-
Figure 3 (continued)

Distribution of mobile means of mortality coefficients for uterine cervical cancer and unspecified malignant neoplasm of uterus in meso-regions of Rio Grande do Sul State, Brazil (standardized to the female population of Rio Grande do Sul State, 2000).

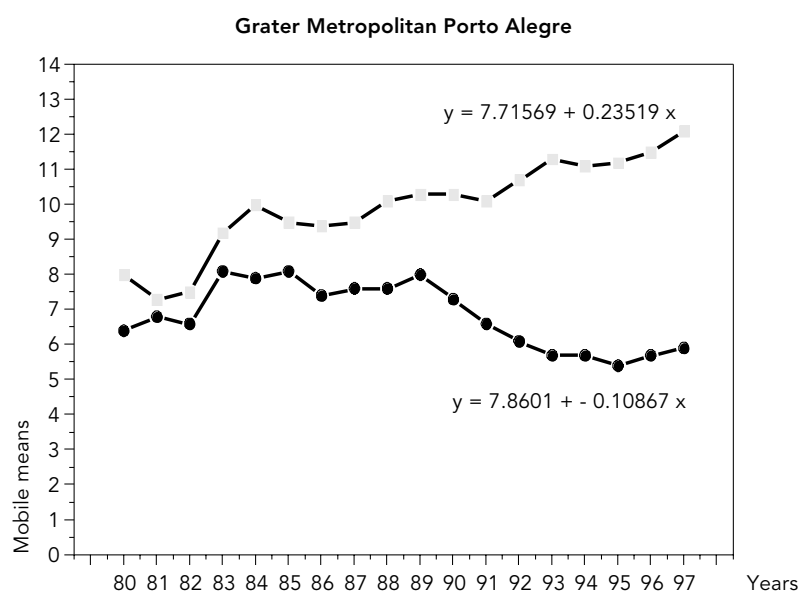

Black line $=$ Malignant neoplasm of uterus, unspecified Gray line = Uterine cervical cancer.

cilitating factor for HPV transmission and subsequent progression of the disease.

However, it was difficult to establish a relationship between the characteristics of each meso-region and the uterine cervical cancer mortality rate, due to the lack of specific data that could be related to uterine cervical cancer as well as quality problems with the existing data. A possible explanation for this trend in the meso-regions could be the greater difficulty in access to health care services in rural areas and smaller towns, far from the State capitals (where most of the resources are concentrated). Still, we should highlight that the same increase observed in the coefficients for Rio Grande do Sul as a whole was also detected in the majority of the meso-regions, suggesting that factors related to this increase in mortality were not specific to the meso-regions, but rather to possible inadequacy of screening throughout the State.

Death during an individual's reproductive age causes social and economic harm to the entire community. Work absenteeism leads to major financial losses for the patient, family, and health system. This study shows an average of nearly 22 potential years of life lost due to uterine cervical cancer and ten potentially produc- 
Figure 4

Mobile means of mortality coefficients for uterine cervical cancer and unspecified malignant neoplasm of uterus

in some States of Brazil, standardized to the world female population, 2000.
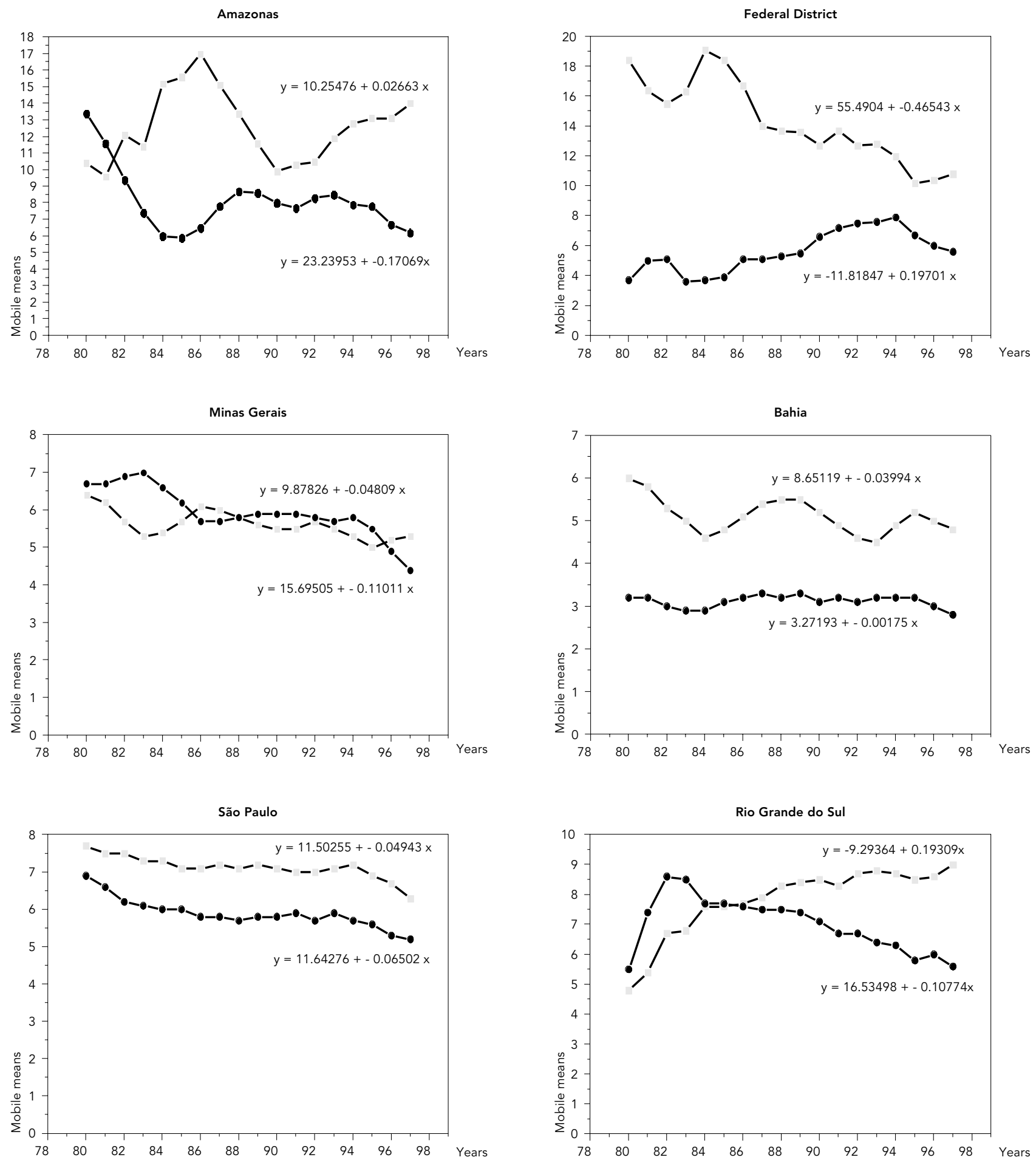

Black line = Malignant neoplasm of uterus, unspecified

Gray line = Uterine cervical cancer. 
tive years of life lost due to this disease, based on the mean life expectancy used for women in the State, or 75 years, and the reference retirement age of 60 years for women. However, it is important to highlight that at the beginning of the study period, the mean life expectancy was less than 75 years, so in this case the means were slightly lower during this period.

The means observed in the evaluation of PYLL and PPYLL from unspecified malignant neoplasm of uterus were similar to those for uterine cervical cancer. This is best shown by the distribution per age interval of mortality coefficients from uterine cervical cancer and unspecified malignant neoplasm of uterus in the initial years of the study, when the mean was higher for the coefficients of unspecified malignant neoplasm of uterus as compared to uterine cervical cancer. Deaths from uterine cervical cancer were more frequent in the 4554-year age interval, while deaths from unspecified malignant neoplasm of uterus were more frequent in the 65-74-year interval. These findings corroborate the hypothesis that cervical neoplasm might have been diagnosed as unspecified malignant neoplasm of uterus because the cases were diagnosed during more advanced stages of the disease.

Solving the problem of lack of basic health services and generating improved opportunity for access by low-income women would allow women to remain active in the workforce and prevent their families from losing them as caregivers and household providers 25 . It is important to emphasize that in addition to the ten years of potentially productive life lost, there is also the time "wasted" with (or lost to) the disease, an experience that tends to be highly unproductive and entails great suffering over the years.

We also observed that Rio Grande do Sul was the only one of the more socially and economically developed States of Brazil which (like the less developed State of Amazonas) shows an upward trend in the mortality rates for both uterine cervical cancer and unspecified malignant neoplasm of uterus. However, the partial coverage of the Mortality Information System and the underreporting of deaths, especially in the North and Northeast of the country, may explain a selection bias in the analysis of these data and could partially explain these findings, although not necessarily modifying the upward trend in Rio Grande do Sul during the study period. Surprisingly, the other States that were analyzed present a downward trend in uterine cervical cancer mortality rates, which as suggested by Fonseca et al. 18
Figure 5

Mortality coefficients for uterine cervical cancer in Rio Grande do Sul State, Brazil, and some countries of the world, 1995

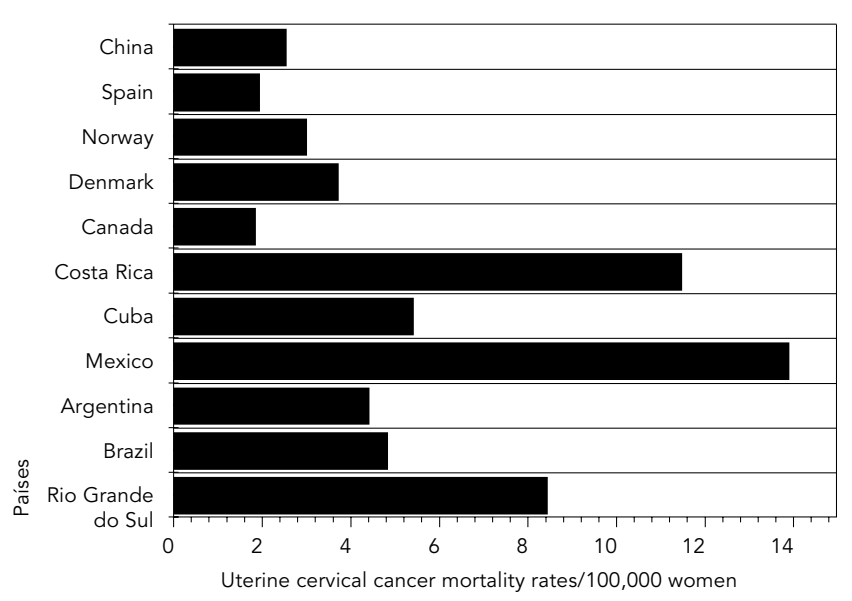

may be related both to improved clinical diagnosis and better filling-out of death certificates and increased Pap smear coverage among the female population.

It is noteworthy that the differences between Rio Grande do Sul and other States of Brazil also occur between countries. The data comparing standardized coefficients from Rio Grande do Sul with several countries corroborate the data from the latter, for example Argentina, Mexico, Costa Rica, and Cuba, which also show high mortality coefficients from uterine cervical cancer. However, China shows low mortality, which has been related to a reduction in the incidence of this neoplasm 21 .

The countries with an important drop in mortality from uterine cervical cancer have in common the implementation of systematic cytological screening programs, with periodic follow-up, thus leading to an impact involving reduction in both incidence and mortality, which probably does not occur in the abovementioned countries. A finding in this study that demonstrates this difference between countries with and without systematic programs is the information on SMR, which was $234.0 \%$ for Rio Grande do Sul as compared to Norway, a country with one of the lowest mortality coefficients from this neoplasm.

Low schooling is an important potential risk factor to be evaluated in susceptibility to uterine cervical cancer, but it was not possible to properly analyze this variable in our study, 
due to the under-recording of the schooling item in the Mortality Information System (49.5\% of death certificates with level of schooling unknown), posing a major limitation resulting from possible errors on death certificates (identification and coding of this variable), which thus becomes a source of measurement bias.

The MoH Women's Health (Saúde da Mulher) project published data on uterine cervical cancer screening programs in various States of Brazil, citing the low coverage of Pap smears, estimated at $8.0 \%$ to $10.0 \%$ of the female population over 20 years of age. According to the WHO, in order to have an epidemiological impact the coverage should reach $85.0 \%$ of women 11 .

\section{Resumo}

A mortalidade por câncer de colo de útero tem diminuído em países desenvolvidos. Entretanto, no Brasil, os dados apontam o câncer de colo de útero como uma das mais freqüentes causas de morte por neoplasia em mulheres, estando em quarto lugar no Rio Grande Sul. Este estudo do tipo série-temporal analisa a mortalidade por câncer de colo de útero e a evolução deste fenômeno no Rio Grande do Sul, no período entre 1979 e 1998. Os dados foram extraídos do Sistema de Informação sobre Mortalidade. Coeficientes de mortalidade padronizados foram analisados por meio de regressão linear simples. Estimou-se o impacto da mortalidade por esta causa sobre a duração de vida esperada para esta população utilizando-se o cálculo dos Anos Potenciais de Vida Perdidos (APVP). Observou-se uma tendência linear positiva dos coeficientes de mortalidade padronizados com incremento anual de 0,17, e o coeficiente anual médio dos óbitos no período foi de 7,58/ 100 mil. Esta doença foi responsável por uma média

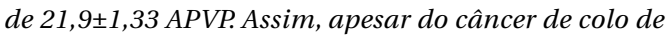
útero ser uma doença prevenível e curável, observa-se um aumento de mortalidade por esta causa, sugerindo falhas nos programas de rastreamento desta doença.

Neoplasia Intra-Epitelial Cervical; Mortalidade; Saúde da Mulher
Since 1997 the State of Rio Grande do Sul has been included in Viva Mulher, which was launched in some areas of Brazil in 1997. However, successful screening requires competence in cytological examination, knowledge of program quality and evaluation, and adequate handling and follow-up of diagnosed lesions. The existence of systematic educational and screening programs for all women after sexual initiation could modify the current situation. Gaps in basic education in the population, lack of knowledge, and persistent fears and taboos surrounding cancer mean that such programs are not demanded by the community, thus highlighting the importance of even greater awareness-raising by governments for citizens' health education and information.

\section{Collaborators}

The two authors worked equally on the drafting and implementation of the project and data analysis, as well as disseminating the data through this article. 


\section{References}

1. National Institute of Health. National Institute of Health consensus development conference statement on cervical cancer. Gynecol Oncol 1997; 66:351-61.

2. Franco EL, Duarte-Franco E, Ferenczy A. Cervical cancer: epidemiology, prevention and the role of human papilomavírus infection. CMAJ 2001; 164:1017-25.

3. Liu S, Semenciw R, Probert A, Mao Y. Cervical cancer in Canada: changing patterns in incidence and mortality. Int J Gynecol Cancer 2001; 11:2431.

4. Canada Cancer Bureau. Cervical cancer in Canada. Population and public health branch. http:// www.hc-sc.gc.ca/hpb/lcdc/bc/updates (accessed in Jan/2002).

5. Schiffman MH, Brinton LA, Devesa SS, Fraumeni JR. Cervical cancer. In: Schottenfeld D, Fraumeni JR, editors. Cancer epidemiology and prevention. Nova York: Oxford University Press; 1996. p. 1090116.

6. Ferlay J, Bray F, Pisani P, Parkin DM. GLOBOCAN 2000: cancer incidence, mortality and prevalence. Version 1.0. Lyon: IARC Press; 2001.

7. Robles SC, White F, Peruga A. Trends in cervical cancer mortality in the Americas. Bull Pan Am Health Organ 1996; 30:290-301.

8. Instituto Nacional de Câncer. Estimativa de incidência e mortalidade por câncer no Brasil em 2003. Rio de Janeiro: Instituto Nacional de Câncer; 2003.

9. Secretaria da Saúde e Meio-Ambiente do Rio Grande do Sul. Estatísticas de saúde: mortalidade. Porto Alegre: Secretaria da Saúde e Meio-Ambiente do Rio Grande do Sul; 1999.

10. Marcus AC, Crane LA. A review of cervical cancer screening intervention research: implications for public health programs and future research. Prev Med 1998; 27:13-31.

11. Ministério da Saúde. Sistema Único de Saúde. Sistema de Informação sobre Mortalidade: 19791998. Dados de declaração de óbito. CD-ROM. Brasília: Ministério da Saúde; 2000.

12. Instituto Brasileiro de Geografia e Estatística. Resolução PR no 51. Boletim de Serviço 1989; 1763 Suppl.
13. World Health Organization. World health statistics. Geneva: World Health Organization; 1990.

14. Organização Mundial da Saúde. Classificação estatística internacional de doenças, lesões e causas de óbitos - nona conferência de revisão. São Paulo: Centro Brasileiro de Classificação de Doenças em Português; 1985.

15. Organização Mundial da Saúde. Classificação estatística internacional de doenças e problemas relacionados à saúde, 10ạ revisão. São Paulo: Centro Colaborador da OMS para a Classificação de Doenças em Português; 1995.

16. Pereira MG. Epidemiologia: teoria e prática. Rio de Janeiro: Guanabara Koogan; 1995.

17. Breslow NE, Day NE. Statistical methods in cancer research: design and analysis of cohort studies. Lyon: IARC Press; 1987.

18. Fonseca LAM, Ramacciotti AS, Eluf Neto J. Tendência da mortalidade por câncer do útero no município de São Paulo entre 1980 e 1998. Rev Bras Epidemiol 2002; Suplemento Especial:34.

19. Koifman RJ, Mattos IE, Monteiro GTR. Koifman S. Tendências da mortalidade por câncer de colo de útero nas capitais do Brasil - 1980 a 1997. Rev Bras Epidemiol 2002; Suplemento Especial:34.

20. Kerr-Pontes LRS, Rouquairol MZ. A medida da saúde coletiva. In: Rouquairol MZ, Almeida Filho $\mathrm{N}$, organizadores. Epidemiologia e saúde. $5 \underline{a}$ Ed. Rio de Janeiro: Editora Medsi; 1999. p. 31-75.

21. Wang PD, Lin RS. Epidemiology of cervical cancer in Taiwan. Gynecol Oncol 1996; 62:344-52.

22. Trent Gynaecological Pathology Quality Assurance Group. Inadequate cervical smear: results of an educational slide exchange scheme. Cythology 1999; 10:16-24.

23. Pete I, Toth V, Bosze P. The value of colposcopy in screening cervical carcinoma. Eur J Gynaecol Oncol 1998; 19:120-2.

24. Faria MAM, Almeida JWR, Zanetta DMT. Mortalidade por câncer na região urbano-industrial da Baixada Santista, SP (Brasil). Rev Saúde Pública 1999; 33:255-61.

25. Nedel FB, Rocha M, Pereira J. Anos de vida perdidos por mortalidade: um dos componentes da carga de doenças. Rev Saúde Pública 1999; 33:460-9.

Submitted on $09 / \mathrm{Jul} / 2003$

Final version resubmitted on 12/Jan/2004

Approved on 01/Mar/2004 